\title{
Breeding for nitrogen efficiency: concepts, methods, and case studies
}

\author{
Edith T. Lammerts van Bueren • \\ Kristian Thorup-Kristensen • Carlo Leifert • \\ Julia M. Cooper $\cdot$ Heiko C. Becker
}

Received: 28 June 2014/ Accepted: 30 July 2014/Published online: 18 August 2014

(C) Springer Science+Business Media Dordrecht 2014

\section{Introduction}

In Europe, the challenge of meeting future food demands while ensuring the sustainability of agricultural systems is increasingly an issue on the public agenda. We have to accept the need of increased efficiency, sustainability and resilience of our agricultural production, while at the same time meeting the emerging challenges such as "feeding the world," "food or fuel," "biodiversity," and "climate change." EUCARPIA, the European association for research in plant breeding, organized a Section meeting on Organic \& Low-input Agriculture in Germany from September 24-26, 2013 at the Georg August

E. T. Lammerts van Bueren ( $₫)$

Wageningen UR Plant Breeding, Wageningen University \& Research Center, P.O. Box 386, 6700 AJ Wageningen, The Netherlands

e-mail: edith.lammertsvanbueren@wur.nl

K. Thorup-Kristensen

Department of Plant and Environmental Sciences,

Faculty of Sciences, University of Copenhagen,

Højbakkegaard Allé 13, 2630 Taastrup, Denmark

C. Leifert · J. M. Cooper

Nafferton Ecological Farming Group (NEFG), Newcastle University, Nafferton Farm, Stocksfield NE43 7XD, UK

H. C. Becker

Department of Crop Sciences, Georg-August-Universität Göttingen, Von-Siebold-Str. 8, 37075 Göttingen,

Germany
University of Göttingen on Breeding for Nutrient Efficiency. This conference focused on the development of new crop breeding strategies to improve nutrient use efficiency as one strategy to address the above mentioned challenges. Next to various contributions on basic concepts and methodologies to improve nutrient efficiency, updates on many ongoing breeding programs and research activities were also presented. The program included results of the NUECROPS project (Improving nutrient efficiency in four major European food, feed and biofuel crops to reduce the negative environmental impact of crop production; EU-FP7 222-645) followed by a panel discussion on the question, "Where do we go next with R\&D into nutrient use efficiency?" In this special issue 16 selected contributions are published. For a more complete overview of the conference please see Becker et al. (2013). In this preface we will shortly summarize the key aspects covered in this issue.

\section{Concepts}

Discussion of genotypic variation in nutrient efficiency is complicated by the fact that there is no generally accepted definition of nutrient efficiency. This problem is discussed in several contributions to this volume (e.g. Nyikako et al., Ospina et al.).

Genetic variation in nitrogen use efficiency is related, but not identical, to adaptation to low-input agriculture or to organic farming (e.g. Konvalina et al.). 
This relationship is very complex and depends on the crop and the environmental conditions. Because trials under organic conditions are often rather difficult, it might be of interest to predict performance under organic farming from trials under low input conventional farming (see Le Campion et al., Šarčević et al.). However, organic agriculture is characterized by very specific conditions e.g. broad rotation and organic fertilizers with slow release of nutrients under cold spring conditions, which are not identical to low input conventional farming applying mineral fertilizers which are water soluble and more readily available (see Mikó et al., Muellner et al.).

Finally it should be mentioned that plant breeders focus on the genetic improvement of one specific crop; however, nitrogen efficiency is not only a characteristic of a specific crop, but a characteristic of a cropping system (see Dresbøll and Thorup-Kristensen, Swain et al.). Therefore effects on the efficiency of the succeeding crops in a crop rotation have to be considered. While breeding for nutrient efficiency is an important approach for increasing overall agricultural nutrient use efficiency, it should also be kept in mind that important aspects of the nutrient use efficiency of cropping systems are mainly the effect of crop management, crop rotation choices and environmental conditions and variability (see the contribution to this issue by Dresbøll and Thorup-Kristensen).

\section{Methods}

For breeding programs it would be extremely helpful to identify easily assessable traits that are related to $\mathrm{N}$ efficiency. One example of this is that in potato high $\mathrm{N}$ efficiency can be highly correlated with late maturity (see Ospina et al., Swain et al., Tiemens-Hulscher et al.). However, many traits contribute to nutrient efficiency but are not easy to identify as they are very much influenced by the interaction with the environmental factors. Chan-Navarrete et al. tried to avoid that environmental influence by testing a set of cultivars on a hydroponics system under controlled greenhouse conditions.

For a better understanding of $\mathrm{N}$ efficiency ecophysiological models can be very helpful (e.g. Dresbøll and Thorup-Kristensen, Kerbiriou et al.). In the future molecular methods will largely increase the prospects for a directed improvement of $\mathrm{N}$ efficiency.
It is possible to identify QTL (Quantitative Trait Loci) for yield and yield components under different $\mathrm{N}$ nutrition regimes, for example in oilseed rape (Bouchet et al.) or barley (Kindu et al.).

Plant roots play a central role in the acquisition of both nutrients and water from the soil. The plant root system can by characterized by a number of traits with complex interactions like root length, rooting depth, root growth rate, root hair density, root hair length and others. Therefore differences in root characteristics are not always directly related to $\mathrm{N}$ efficiency or yield as shown for perennial ryegrass (see Deru et al.). Moreover it is very difficult to measure root traits under realistic conditions. One interesting approach is to use soil columns of two meter length positioned outdoors to simulate root growth in the natural environment as presented by Ytting et al.

\section{Case Studies}

This volume contains many examples of successful work in improving nitrogen efficiency. Nearly half of the contributions focus on wheat (Konvalina et al., Le Campion et al., Mikó et al., Muellner et al., Šarčević et al., Swain et al., Ytting et al.). But also a variety of other crops with very different growth and development are covered including barley (Kindu et al.), potato (Swain et al., Tiemens-Hulscher et al., Ospina et al.), oilseed rape (Bouchet et al., Nyikako et al.), perennial ryegras (Deru et al.), spinach (ChanNavarrete et al.) and lettuce (Kerbiriou et al.).

Finally, we hope that this issue will inspire researchers and breeders to continue developing better understanding of the underlying mechanisms and traits related to nitrogen uptake and utilisation efficiency. Ultimately the goal is to find practical and efficient selection tools for breeders to incorporate in a selection programme for nitrogen efficient cultivars.

\section{Reference}

Becker H, Lammerts van Bueren ET, Leifert C, Thorup Kristensen K (2013) Breeding for nutrient efficiency. Conference booklet of the joint meeting of Eucarpia section organic \& low-input agriculture and EU NUE CROPS project, Georg August Universität Göttingen, Germany, 24-26 September 2013, http://www.uni-goettingen.de/de/ 415791.html. Accessed 13 July 2014 